\title{
¿Por qué no a la impunidad? Una mirada desde las teorías comunicativas al papel de la persecución penal en la justicia de transición*
}

\section{Why against impunity? The role of criminal prosecutions in transitional justice from the point of view of communicative theories}

\author{
Dra. Daniela Accatino \\ Universidad Austral de Chile \\ daccatino@uach.cl
}

\begin{abstract}
Resumen: El trabajo explora el reforzado papel que, tanto en las prácticas domésticas como en el derecho internacional, ha tendido a reconocerse a la respuesta penal en el abordaje de un pasado de violaciones graves y sistemáticas de los derechos humanos. Su objetivo es reabrir la discusión sobre la justificación ético-política del recurso a la persecución penal en contextos de transición política, considerando las perspectivas que puede aportar la teoría comunicativa de la pena, del derecho penal y del proceso penal desarrollada por Antony Duff. Se sostiene que la comprensión, a partir de esos insumos teóricos, de los actos de terror estatal como agravios públicos, así como la reparación moral que ese reconocimiento significa para las víctimas y la inclusión comunicativa de los perpetradores al ser llamados a responder, ofrecen claves importantes para justificar la contribución de la respuesta penal en la reconstitución de una comunidad política quebrada por ese pasado de violencia.
\end{abstract}

Palabras claves: justicia de transición - proceso penal - derechos humanos - Antony Duff

Abstract: The paper explores the ongoing process of entrenchment of prosecutions in transitional justice contexts. Its purpose is to discuss the ethical and political foundations of this kind of accountability, considering the insights that the communicative theory of criminal law, developed by Antony Duff, can offer. It will be argued that the understanding of bureaucratic atrocities as public wrongs, the moral repair that the sharing of that wrong by the other citizen means for the victims and the communicative inclusion of the perpetrators that are called to answer for their crimes, can justify the place of prosecution in the reconstitution of a political community broken by a past of massive violence.

Key words: transitional justice - prosecutions - human rights - Antony Duff

"Here we are, demanding justice and meting out punishment in accordance with our sense of justice,

\footnotetext{
* Este artículo ha sido desarrollado en el marco del Proyecto FONDECYT 1151528 "Prueba judicial y justicia transicional" del que la autora es investigadora responsable. Agradezco los comentarios de Cath Collins y Jonatan Valenzuela, quienes leyeron una versión preliminar. Una primera aproximación a las ideas aquí presentadas fue discutida también en las Jornadas Nacionales de Filosofía del Derecho del año 2016, en Valdivia, donde recibió valiosas observaciones de los participantes, en particular de Enzo Solari, Miguel Orellana Benado, Juan Pablo Mañalich y Carolina Bruna.
} 
while, on the other hand, this same sense of justice informs us that all our previous notions about punishment and its justification have failed us" $\mathrm{H}$. Arendt $(1964,25)$.

\section{Justicia de transición y justicia penal}

La reflexión sobre la forma en que una comunidad política que ha sufrido violaciones graves y sistemáticas de derechos fundamentales en contextos de dictadura o conflicto armado debiera enfrentar ese pasado de atrocidades masivas se ha articulado, a partir de fines de los años ochenta del siglo pasado, en torno a la noción de "justicia transicional"1. Desde sus inicios ese campo de investigación y de activismo se ha estructurado en torno a la identificación de un conjunto de "componentes" o "mecanismos", que corresponden a diversas dimensiones relevantes de acción dirigidas a abordar los abusos pasados, entre las que se suele incluir: la reconstrucción de la verdad, la justicia, las reparaciones, las reformas institucionales que garanticen la no repetición y, también, en los últimos años, la memoria $^{2}$. Y, en ese contexto, la dimensión de justicia se entiende referida, siempre, a la justicia penal. Lo expresa bien Ruti Teitel cuando dice que "la pena domina nuestra comprensión de la justicia transicional”’3.

Así se observa en las conferencias internacionales que, a fines de los años ochenta, fueron constituyendo el campo disciplinar de la justicia de transición. Tras la estela de los Juicios de Núremberg, y con los ojos puestos en la experiencia argentina -donde en 1985 tenía lugar el Juicio a las Juntas y en 1986 se dictaban las Leyes de Punto Final y de Obediencia Debida-, en ellas fue crucial la cuestión de un posible fundamento en el derecho internacional para un imperativo de persecución penal de los actos pasados de terror estatal, así como las preguntas por su alcance y su limitación en virtud de consideraciones de prudencia política $^{4}$. Y hoy, treinta años después. podemos constatar que el activismo contra la impunidad se mantuvo vivo en las transiciones donde la tensión entre justicia y

\footnotetext{
${ }^{1}$ Cfr. sobre los orígenes de ese concepto y del campo disciplinar y de acción que en torno a él se articula, PAIGE, Arthur, "How 'transitions' reshaped human rights: a conceptual history of transitional justice", Human Rights Quarterly, vol. 31 (2009), pp. 321-367, passim.

${ }^{2}$ Así lo ponen de relieve, también, PAIGE, "How 'transitions'...", cit. nota no 1 , pp. 325 y 355 y ss., analizando la estructura de las primeras conferencias internacionales a las que asigna un papel fundacional, y DE GREIFF, Pablo, "Theorizing transitional justice", Nomos , vol. LI (Transitional Justice) (2012), pp. 31-77, p. 31. Esa estructura puede observarse ya, por ejemplo, en el pionero e influyente compendio de tres volúmenes editado en 1995 por KRITZ, Neil, Transitional justice: how emerging democracies reckon with former regimes, Washington: USIP, 1995; también en otro texto clásico: TEITEL, Ruti, Transitional justice, Oxford: Oxford University Press, 2000; y en documentos internacionales como el Reporte de la Secretaría General de la ONU de 2004 "The rule of law and transitional justice in conflict and post-conflict societies". Sobre la emergencia de la memoria como dimensión de la justicia transicional, cfr., por ejemplo y con referencia a Chile, STERN, Steve J., "Memory. The curious history of a cultural code word", Radical History Review, $\mathrm{N}^{\mathrm{o}} 124$ (2016), pp. 117-128, passim.

${ }^{3}$ TEITEL, Transitional justice, cit. nota n², p. 27.

${ }^{4}$ Cfr. PAIGE, "How 'transitions'...", cit. nota $\mathrm{n}^{\circ} 1$, p. 352. A la centralidad de esas preguntas sobre la persecución de responsabilidades penales a través de procesos judiciales en los contextos de transición se refiere también COLLINS, Cath, Post-transitional justice. Human rights trials in Chile and El Salvador, Pennsylvania: The Pennsylvania State University Press, 2010, p. 14.
} 
estabilidad tendió a resolverse inicialmente a favor de la última, y que progresivamente la persecución penal frente a las violaciones graves y sistemáticas de derechos humanos ha ido reemergiendo y acrecentando su protagonismo, tanto en las prácticas domésticas, particularmente en Latinoamérica, como en el derecho internacional ${ }^{5}$.

Chile ha sido parte, como se sabe, de estos vaivenes. Estuvo, por un lado, involuntariamente en primera plana como actor de un hito en el proceso que fue forjando ese giro hacia el reforzamiento de la persecución penal, en virtud de la resonancia internacional que tuvo la detención en Londres de Pinochet en 1998.Y, por otro lado, ese giro se ha manifestado también internamente a través de la progresiva inaplicación judicial del Decreto Ley de Amnistía, que se consolidó en la década pasada y que se expresa actualmente en más de trescientas causas con sentencias condenatorias firmes y más de mil trescientos procesos penales en curso ${ }^{6}$.

Se ha discutido bastante acerca de lo que puede explicar este desplazamiento punitivista, como si su justificación, tras años de resistencia contra la impunidad, fuera en cierto modo evidente; como si bastara la intuición -expresada por la cita anterior de Teitel y también por la de Arendt que abre este trabajo- de que, frente a una política sistemática de tortura, muerte y desaparición, la justicia requiere el castigo de los responsables. Pero -como se

\footnotetext{
${ }^{5}$ Sobre las diversas experiencias a nivel nacional, principalemente en Latinoamérica, aunque también con antecedentes en Europa, donde el pasado nazi ha vuelto periódicamente a ser objeto de procesos penales internos, cfr., por ejemplo, HEBERER, Patricia y MATTHAÜS, Jürgen (eds.), Atrocities on trial. Historical perspectives on the politics of prosecuting war crimes, Lincoln: University of Nebraska Press, 2008; COLLINS, Post-transtional justice..., cit. nota ${ }^{\circ} 4$; COLLINS, Cath, SKAAR, Elin y GARCÍA-GODOS Jemima (eds.), Transitional justice in Latin America: the long road from impunity towards accountability, Abington: Routledge, 2016; SIKKINK, Katherine, The justice cascade. How human rights prosecutions are changing world politics, New York - London: W. W. Norton \& Company, 2011; FORNASARI, Gabriele, Giustizia di transizione e diritto penale, Torino: Giappichelli, 2013; MARGARELL, Luisa y FILIPPINI, Fernando (eds.), La justicia penal en la transición peruana, Nueva York: ICTJ, 2006; QUINTEROS, Víctor Manuel (ed.), Judicialización de violaciones de derechos humanos: aportes sustantivos y procesales, Lima: AECID, 2010; BOUVIER, Hernán, GULLI, Belén y IOSA, Juan (eds.), El juzgamiento de los delitos de lesa humanidad en la Argentina postdictatorial, Córdoba: Ferreyra Editores, 2014. Con respecto a la evolución en el derecho internacional, tanto en el ámbito del derecho penal internacional, a raíz de la constitución de la Corte Penal Internacional, como en el ámbito del derecho internacional de los derechos humanos y la jurisprudencia de los sistemas regionales, con la progresiva consolidación, particularmente a nivel de la Corte Interamericana de Derechos Humanos, de un deber estatal de investigar, juzgar y llegado el caso sancionar a los responsables de graves violaciones a lso derechos humanos, cfr. dos miradas generales en TEITEL, Ruti, "Transitional justice and judicial activism -a right to accountability?", Cornell International Law Review, Vol. 48 (2015), pp. 385-422 y McGONINGLE, Brianne, "Nuremberg's legacy within transitional justice: prosecutions are here to stay", Washington University Global Studies Law Review, Vol. 15, Issue 4 (2016), pp. 559-574.

${ }^{6}$ Cfr. para una mirada histórica del rol del poder judicial chileno, HILBINK, Lisa, Jueces y política en democracia y dictadura. Lecciones desde Chile, México DF: FLACSO, 2014; para una caracterización de la situación actual COLLINS, Post-transitional justice.., cit. nota nº 4 , pp. 77 y ss. y COLLINS, Cath, "La política de la justicia: Chile más allá del caso Pinochet", en COLLINS, Cath, HITE, Katherine y JOIGNANT, Alfredo (eds.), Las políticas de la memoria en Chile: desde Pinochet a Bachelet, Santiago: Ediciones Universidad Diego Portales, 2013, pp. 85-115. Agradezco al Ministro Sergio Muñoz, Coordinador nacional de causas de derechos humanos en la época en que este artículo fue escrito, y, especialmente, a quienes lo apoyaron en esa gestión, Gloria Jacome, Claudia Cáceres y Sandra Stuardo, por la ayuda en el acceso a la información sobre las causas.
} 
advierte en la segunda parte de la misma cita de Arendt- esa intuición se enfrenta con aporías que ponen en jaque nuestras nociones sobre la pena y su justificación. Es sobre ese problema, el de la justificación, desde un punto de vista filosófico jurídico y político criminal, de este modo de responder a las atrocidades del pasado, que me propongo volver en este artículo, analizando qué pueden decirnos al respecto algunos desarrollos recientes en la filosofía de la pena, del delito y del proceso penal. En particular me interesa explorar en este trabajo el aporte de la teoría comunicativa que elabora Antony Duff. Son varias las razones de esa elección. Por una parte, Duff se inserta en una corriente más amplia de esfuerzos teóricos por conectar la filosofía del derecho penal con la teoría de la democracia, lo que se expresa en el papel central que en su concepción de la responsabilidad penal juega la condición de ciudadano de una comunidad política organizada democráticamente, ante la cual se responde ${ }^{7}$. Como argumentaré luego, esta perspectiva ofrece una reconstrucción del sentido "público" de la imputación de responsabilidad penal que resulta especialmente atractiva en contextos de justicia transicional. Por otra parte, al reformular una concepción retributiva de la pena y distanciarse del instrumentalismo propio de las teorías preventivas y, en el contexto de la justicia de transición, de las teorías que conectan la justificación de la respuesta penal con un fin educativo, la propuesta de Duff elude varias dificultades a las que, como veremos, están expuestas esas teorías en ese contexto especial. De ahí que pueda ofrecer, además, un terreno conceptual apropiado para abordar las objeciones más difíciles, referidas a la inadecuación de las categorías propias de la responsabilidad penal individual para enfrentar una política de terror impuesta burocráticamente por el Estado. Finalmente, la teoría de Duff, a diferencia de otras filosofías del derecho penal, integra además una concepción normativa del proceso penal, incorporando a su reflexión también esa fase de la imputación de responsabilidad.

Sin perjuicio del interés puramente filosófico de la pregunta por la justificación de la respuesta penal en contextos de justicia transicional, esa reflexión puede ser también relevante prácticamente, desde el punto de vista de la deliberación pública sobre el ajuste de cuentas con el pasado de violencia que subyace, todavía, a las instituciones del Chile actual. Por una parte, ese análisis puede ofrecer categorías y argumentos para dar forma a un "relato" que dé sentido a la extenuante empresa de investigar en procesos criminales los miles de casos de desaparición, ejecución política y tortura cometidos durante la dictadura, en un contexto en el que por no haber sido el "giro judicial" fruto de una decisión política de gobierno - a diferencia, por ejemplo, de las políticas de verdad a través de la Comisiones o de las políticas de reparación-, no ha habido ningún discurso público que lo sustente y articule. Por otra parte, la reflexión que aquí se propone puede ofrecer insumos para reflexionar críticamente sobre esa experiencia. Ya sea para pensar, a contraluz de un modelo normativo, en los límites de la forma que ha asumido esa respuesta penal (en los límites, por ejemplo, de la tramitación escrita, conforme al antiguo procedimiento penal), o bien para enfrentar, desde ese soporte teórico, las muchas cuestiones que la respuesta penal al terror hoy suscita, como, por ejemplo, las preguntas por la aplicación en estas causas de

\footnotetext{
${ }^{7}$ Sobre los esfuerzos teóricos para el desarrollo de un "derecho penal democrático" y los aportes y problemas de la posición de Duff en ese contexto cfr. GARGARELLA, Roberto, Castigar al prójimo. Por una refundación democrática del derecho penal, Buenos Aires: Siglo XXI, 2016, pp. 165 y ss. y MAÑALICH, Juan Pablo, "Responsabilidad, autoridad y democracia. Una exploración crítica de la filosofía del derecho penal de Antony Duff", Discusiones, No 17 (2016), pp. 167-219, passim.
} 
la denominada prescripción gradual $^{8}$, o por la ejecución de la pena y el acceso a beneficios penitenciaros por parte de los condenados 9 .

\section{Una teoría comunicativa de la pena y del proceso penal}

El punto de partida de las teorías comunicativas se encuentra en la reconstrucción de una aproximación retribucionista de la pena, mediada, además, por su comprensión en términos expresivos $^{10}$. A partir de esta imagen de la pena como "un artefacto convencional para la expresión de actitudes de resentimiento e indignación, y de juicios de desaprobación y de reprobación, de parte de la autoridad punitiva o de aquellos a cuyo nombre la pena es infligida" ", el "giro comunicativo" transforma la expresión en relación comunicativa articulada triádicamente, entre quien ha sido declarado culpable, la o las víctimas directas y la comunidad política ante la cual se responde ${ }^{12}$.

Al sujeto penado la pena se dirige, bajo esta última concepción, pretendiendo su aceptación del reproche que ella expresa como justificado. Y es precisamente para dar cuenta de esta orientación al "entendimiento recíproco y racional" que Duff considera preferible hablar de "comunicación" en lugar que de "expresión", pues de ese modo se enfatiza que la pena no debe ser solo manifestación unidireccional de algo a alguien, sino proceso bidireccional en el que se aspira a comprometer a y requerir una respuesta adecuada de otro agente racional $^{13}$. Pero la pena $-y$ como veremos enseguida, antes que ella, el proceso penaltambién constituye un acto de comunicación respecto de la víctima, mediante el cual la

${ }^{8}$ Cfr. FERNÁNDEZ, Karinna y SFERRAZZA Pietro, "La aplicación de la prescripción gradual en casos de violaciones de derechos humanos", Estudios Constitucionales, Vol. 7, № 1 (2009), pp. 299-330, passim.

${ }^{9}$ Cfr. sobre estas discusiones, COLLINS, Cath et. al., "Verdad, justicia, reparaciones y memoria", en CENTRO DE DERECHOS HUMANOS DE LA UNIVERSIDAD DIEGO PORTALES, Informe anual sobre derechos humanos en Chile 2017 (http://www.derechoshumanos.udp.cl/derechoshumanos/index.php/informeddhh-2017), passim.

${ }^{10}$ Cfr. respecto de esta comprensión expresiva FEINBERG, Joel, "The expressive function of punishment", en ID., Doing and deserving, Princeton: Princeton University Press, 1970, pp. 95-118, passim у PRIMORATZ, Igor, "Punishment as language", Philosophy, $\mathrm{N}^{\circ} 64$ (1989), pp. 187-205, passim. Sobre la forma en que una concepción expresiva de la pena puede articularse con una teoría retribucionista, cfr. DUFF, Antony, Punishment, communication and community, Oxford: Oxford Universtity Press, 2001, pp. 27ss.

${ }^{11}$ FEINBERG, "The expressive function", cit. nota n' ${ }^{\circ} 10$, p. 98.

${ }^{12}$ Una caracterización general del "giro comunicativo" en la teoría de la pena y el derecho penal se puede ver en GÜNTHER, Klaus, "Criminal law, crime and punishment as communication", Normative Orders Working Paper 02/2014, Normative Orders Cluster of Excellence at Goethe University Frankfurt/Main, passim.

${ }^{13}$ DUFF, Punishment, communication,... cit. nota $\mathrm{n}^{\circ} 10$, p. 79 . La respuesta apropiada que el reproche pretende lograr a través de la persuasión racional del sujeto penado, es su arrepentimiento, derivado de la aceptación de la incorrección de su acción; el reconocimiento de la necesidad de evitar realizar nuevamente la misma acción; y su reconciliación, a través del perdón, con la víctima. Cfr. DUFF, Punishment, communication ..., cit., nota $\mathrm{n}^{\circ} 10$, pp. 107-112 y una discusión de esta concepción en VALENZUELA, Jonatan, "La pena como penitencia secular. Apuntes sobre el sentido de la ejecución de la pena", Revista de Derecho (Valdivia), Vol. XXIII, N 1 (2010), pp. 255-268. Esta concepción comunicativa de la pena abre, por supuesto, una discusión respecto de las formas de punición aceptables, que no impliquen una exclusión del penado de la comunidad política, que sean compatibles con su reconocimiento como un igual agente moral, racional y autónomo, capaz de reconocer la relación valorativa entre el comportamiento que es objeto del reproche y la respuesta punitiva, y que constituyan un método apropiado para obtener ese entendimiento comunicativo. 
comunidad política reconoce y comparte como público el agravio que ha sufrido ${ }^{14}$. Y, por último, a través de la pena se da cuenta además al resto de los ciudadanos de que los valores comunes que las normas penales quebrantadas encarnan son tomados en serio ${ }^{15}$.

Vale la pena detenernos brevemente en estas ideas y, en particular, en la concepción normativa que Duff desarrolla del delito como public wrong. El punto es que, si se trata de justificar la mantención del sistema de derecho penal como un particular tipo de institución jurídica, es necesario explicar por qué el Estado debiera tipificar algunos tipos de conducta como delitos, en lugar de someterlos a modos no penales de regulación jurídica. La respuesta de Duff es que:

"Si nos tomamos en serio los valores que nos definen como comunidad política, así como la demanda de que nos mostremos recíprocamente el debido respeto y consideración como conciudadanos, entonces tomaremos en serio las violaciones de esos valores y de esa demanda, marcándolos y condenándolos públicamente como delitos"16.

De ese modo, sostiene el autor, nos aseguramos, en la mayor medida razonable, que sus perpetradores sean llamados a responder en juicio y sean sometidos a una pena retributiva, que se distingue de otras sanciones por su significado de reproche retrospectivo. No es posible examinar aquí detenidamente mediante qué criterios precisa Duff esta fórmula. Lo que interesa destacar es que la responsabilidad penal debiera referirse a agravios (wrongdoings) que son definidos como "públicos" en el sentido de que nos conciernen a todos como miembros de la comunidad política y merecen una respuesta formal y pública, de censura o condena. Duff los caracteriza también como "agravios que compartimos", en el sentido que:

"[n]o debemos dejar a la víctima perseguir sola su agravio, sino que debemos perseguirlo colectivamente con ella y por ella; su atacante debe responder no solamente a ella, sino a nosotros como sus conciudadanos, de ella y de él, por su agresión a ella y por la violación de los valores fundamentales que nos definen como comunidad política" ${ }^{\prime 17}$.

La pretensión comunicativa de la pena se proyecta también, en la teoría de Duff, al proceso penal. A través del juicio penal el sujeto a quien se imputa haber cometido un delito es llamado por la comunidad política a responder de ese cargo $\mathrm{y}$, si es luego condenado, a responder por su conducta. A través del proceso penal la comunidad política se dirige al acusado como ciudadano, reconociéndolo como miembro de esa comunidad normativa, por cuyos valores comunes está a la vez vinculado y protegido, y como agente responsable,

\footnotetext{
${ }^{14}$ DUFF, Punishment, communication,,,, cit., nota $\mathrm{n}^{\circ} 10$, p. 28.

${ }^{15}$ DUFF, Punishment, communication, ... cit., nota ${ }^{\circ} 10$, pp. 28 y 112 ss.

${ }^{16}$ DUFF, Antony, Answering for crime, Oxford and Portland: Hart Publishing, 2007, p. 88.

${ }^{17}$ DUFF, Answering for crime, cit. nota $\mathrm{N}^{\circ} 16$, p. 141.
} 
capaz de responder de manera apropiada a razones, reconociéndolas y deliberando sobre ellas $^{18}$.

Desde esta perspectiva, además de tener un valor instrumental como preludio del mensaje de reproche expresado por la pena, el proceso penal tiene un valor comunicativo intrínseco en tanto llamado a responder del cargo de haber cometido un agravio "público", que concierne por eso precisamente a todos los miembros de la comunidad política. Un valor comunicativo respecto del acusado, a quien se trata no como objeto de investigación sino como sujeto capaz de responder a los cargos y a las pruebas y a quien, en caso de ser condenado, la sentencia le habla del injusto del que se ha probado que es culpable, expresando un juicio razonado sobre su conducta, que se espera acepte y pueda hacer propio. Pero también un valor comunicativo como respuesta debida al delito, que muestra que la comunidad lo toma en serio como tal, como agravio público, que comparte con la víctima, reconociéndola de ese modo, o reafirmando su reconocimiento, como parte de la comunidad.

Delineada de este modo, aunque sea a trazos gruesos, la teoría comunicativa de la pena y del proceso penal, veremos en la siguiente sección si ella puede ofrecer un marco normativo para la justificación de la persecución penal en contextos de transición política.

\section{Una justificación comunicativa de la respuesta penal en contextos de transición política}

La identificación del significado de la pena como símbolo convencional para la comunicación del reproche merecido a quien ha perpetrado un agravio que afecta los valores que nos definen como comunidad política y la caracterización del llamado a responder al acusado a través del proceso penal como respuesta debida a través de la cual se reconoce el injusto sufrido por la víctima como público y compartido por la comunidad, ofrecen, a mi juicio, varias claves significativas para reconstruir el sentido en que la persecución penal de las atrocidades masivas y sistemáticas puede justificarse como exigencia de justicia.

\subsection{Los actos de terror estatal como agravios públicos}

La primera clave la ofrece la noción de "agravio público" como el tipo distintivo de injusto merecedor de reproche penal. Como veremos, una de las objeciones contra la respuesta penal a las atrocidades cometidas en virtud de una política sistemática de exterminio y terror, se apoya en la imposibilidad de dar cuenta de la "radicalidad" de ese mal a través las categorías del derecho penal ordinario. Desde la perspectiva del derecho penal sólo se harían visibles los delitos individuales, cometidos respecto de cada víctima: cada homicidio, cada violación, cada secuestro, cada inhumación ilegal, cada inflicción de torturas. Su carácter burocrático y masivo, su dimensión de política sistemática emprendida

\footnotetext{
${ }^{18}$ Cfr. DUFF, Answering for crime, cit. nota $\mathrm{N}^{\circ} 16$, pp. 175ss. y, especialmente, DUFF, Antony, FARMER, Lindsay, MARSHALL, Sandra y TADROS, Victor, The trial on trial III: Towards a normative theory of criminal trial, Oxford and Portland: Hart Publishing, 2006, pp. 127ss.
} 
por el propio aparato estatal, resultaría omitida e invisibilizada por la respuesta penal. El punto es importante y volveremos a ocuparnos de él más adelante. Lo que me interesa observar ahora es, por así decirlo, la imagen en negativo (en sentido fotográfico) de esa crítica. Esto es, advertir, qué es lo que el reproche penal de esos actos individuales sí visibilizaría. Lo que haría visible es que cada uno de esos actos constituye un agravio público, un acto que ofende los valores básicos que definen a la comunidad política que por eso los juzga y condena ${ }^{19}$.

Al contrario de lo que afirma Fernando Atria, en un texto donde desarrolla la misma objeción antes apuntada y sostiene que frente a las formas propiamente políticas de abordar un pasado de terror estatal, la vía judicial supondría una privatización del problema, una comprensión del problema "como uno privado, de personas que fueron brutalmente dañadas en el pasado y que requieren reparación" ${ }^{20}$, la persecución penal expresaría, bajo una concepción comunicativa, el carácter público de ese agravio, que concierne por eso no sólo a la víctima sino a toda la comunidad política. Atria admite que los procesos judiciales han producido un registro autorizado de las violaciones a los derechos humanos, haciéndolas públicas, pero limita el sentido de esa publicidad a que ellas "se saben y se sabe que se saben" "21, a una suerte de conciencia compartida del sufrimiento de las víctimas, que, señala el mismo Atria, sería análoga a la que "producen las periódicas campañas de solidaridad con los que, por una u otra razón han sido tratados duramente por la vida: con quienes ven sus viviendas inundadas, o con quienes experimentan discapacidades físicas" 22 . Una publicidad, pareciera, no muy diferente a la que genera un noticiario en horario estelar o la primera plana en un diario; una publicidad que puede producir una empatía análoga, como dice Atria, a la que podemos sentir respecto de "personas cuyas vidas son desbaratadas por una calamidad natural", capaz de hacernos reaccionar "porque sentimos su dolor, pero es $s u$ dolor" 23 . La concepción comunicativa de la pena y del proceso penal permite advertir un sentido, por completo diferente, en el que la justicia penal reconocería el agravio sufrido por la víctima como público, un sentido en el que se testimonia que, precisamente al contrario de lo que ocurre con un desastre natural, lo que la víctima ha sufrido es el resultado de la acción injusta de otro, una acción injusta que afecta los valores que nos definen como comunidad política y que la comunidad por eso comparte, llamando a sus perpetradores a responder.

La concepción comunicativa permite negar en el plano normativo la representación que Atria ofrece de la respuesta judicial como forma de privatización, asignando a los procesos penales una pretensión normativa de publicidad, una pretensión de dar "testimonio del

\footnotetext{
${ }^{19}$ De hecho, la clase de actos a través de los que una política de terror se materializa respecto de sus víctimas -homicidios, violaciones, secuestros, lesiones- son parte de lo que Duff identifica como parte del "núcleo mínimo" de agravios "categóricos", que sería difícilmente imaginable que no sean definidos como delitos en cualquier sistema jurídico (agravios que representan, sostiene Duff, contravenciones serias de los valores fundamentales de cualquier comunidad política como quiera que se definan a sí mismas, sea en términos de autonomía, derechos, bienestar). Cfr. DUFF, Answering for crime, cit. nota $\mathrm{N}^{\circ} 16$, p. 143.

${ }^{20}$ ATRIA, Fernando, "La hora del derecho: los 'derechos humanos' entre la política y el derecho", Estudios Públicos, $\mathrm{N}^{\circ} 91$ (2003), pp. 45-89, p. 79.

${ }^{21}$ ATRIA, "La hora del derecho...", cit. nota $\mathrm{N}^{\circ} 20$, pp. 58-9.

${ }^{22}$ ATRIA, "La hora del derecho....", cit. nota $\mathrm{N}^{\circ} 20$, p. 80.

${ }^{23}$ ATRIA, "La hora del derecho...", cit. nota $\mathrm{N}^{\circ} 20$, p. 80.
} 
reconocimiento" 24 de que lo que las víctimas han experimentado no es un agravio privado que ponga en juego únicamente su sufrimiento individual. Pero esto no obsta a que la representación de Atria pueda constituir una descripción, más o menos verdadera, de la forma en que los juicios de derechos humanos son de hecho retratados en la prensa o percibidos en cierta opinión pública. Más claras en su sentido descriptivo son las afirmaciones similares que realiza Cath Collins del riesgo que esos procesos sean tratados como "litigios privados entre los querellantes -familiares y sobrevivientes- y los antiguos agentes" que son acusados ${ }^{25}$. Un riesgo que Collins asocia al modo de implementación de esos juicios, bajo un modelo procesal en el que no hay una parte acusadora pública, donde el impulso procesal ha correspondido fundamentalmente a los querellantes, resultando muy posterior en el tiempo tanto la iniciativa de oficio, como la intervención del Programa de Derechos Humanos (primero dependiente del Ministerio del Interior, actualmente del Ministerio de Justica), que está limitada legalmente, además, sólo a los casos de víctimas ejecutadas y detenidas desaparecidas ${ }^{26}$. Desde la perspectiva de un modelo normativo de proceso penal articulado a partir de una concepción comunicativa estas condiciones de implementación podrían ser criticadas como defectuosas por no ajustarse al carácter público de la ofensa que mediante ese proceso se persigue.

\subsection{La reparación moral de las víctimas a través de la restauración de su pertenencia a la comunidad política}

El reconocimiento de la publicidad del agravio sufrido, que de acuerdo con una concepción comunicativa expresan la pena, y antes de ella, el proceso penal, puede constituir una forma de reparación respecto de las víctimas. Una forma reparación distinta del resarcimiento material del daño privado sufrido (a lo que podrán apuntar otra clase de medidas reparatorias o bien procesos civiles de indemnización), que se dirige no al daño sino al injusto padecido ${ }^{27}$ y que al comunicar que ese agravio es compartido por la comunidad política, reafirma la calidad de la víctima como miembro de ella ${ }^{28}$.

\footnotetext{
${ }^{24}$ Se trata de la elocuente fórmula que FEINBERG, "The expressive function”, cit. nota n¹0, p. 103, usa para referirse a la pena.

${ }^{25}$ COLLINS, Cath, "Human rights defense in and through the courts in (post) Pinochet Chile", Radical History Review , N 124 (2016), pp. 129-140, p. 135

${ }^{26}$ Collins vincula también el riesgo de privatización a la actual presencia mediática de las controversias sobre las condiciones de ejecución de las penas, en las que las asociaciones de familiares y víctimas son constantemente enfrentadas a responder si esas formas de cumplimiento las "satisfacen", mientras del otro lado abogados y familiares de los condenados reclaman por la dureza de la encarcelación tratándose de personas de avanzada edad, que en algunos casos están, además, enfermas. Cfr. COLLINS, "Human rights defense...", cit. nota $\mathrm{N}^{\circ} 25$, p. 135.

${ }^{27}$ Sobre esta noción de reparación moral cfr. DUFF, Punishment, communication,,,, cit., nota $\mathrm{n}^{\circ} 10$, , pp.9496.

${ }^{28}$ Cfr. también GÜNTHER, Klaus “The criminal law of 'guilt' as subject of a politics of remembrance in democracies', en CHRISTODOULIDIS, Emilios y VEITCH, Scott (eds.), Lethe's law, Oxford: Hart Publishing, 2001, pp. 3-15, p. 13 se refiere al papel reparatorio que el reproche penal y la adscripción de culpabilidad cumplen respecto de la víctima, dado el esquema binario con el que sufrimiento es atribuido o bien a la acción injusta de un tercero o bien a la fatalidad o la propia responsabilidad de la víctima.
} 
Esta segunda clave que aporta la concepción comunicativa de la reacción penal resulta especialmente significativa en contextos de transición ${ }^{29}$, dado que una política de desaparición, ejecución y tortura sistemática, ejercida por órganos represivos del Estado, niega precisamente a las víctimas la calidad de miembros de la comunidad política, al situarlas en "un espacio en el que la ley se suspende totalmente", donde "los propios conceptos de derecho subjetivo y de protección jurídica ya no tenían sentido alguno" como sostiene Giorgio Agamben al analizar la estructura jurídico-política de los campos de concentración. Un lugar donde:

"[se llegó a] privar tan completamente de sus derechos y prerrogativas a unos seres humanos, hasta el punto que realizar cualquier tipo de acción contra ellos no se considerara ya como un delito (en este punto, en efecto, todo se había hecho verdaderamente posible)" ${ }^{\prime 30}$.

\subsection{El llamado a los perpetradores a responder}

La concepción comunicativa ilumina cómo en un contexto de transición política la persecución penal podría representar una instancia de reconstitución de la comunidad política en un sentido adicional. Pues al llamar a los perpetradores a responder de sus actos, los incluye en ese "ritual de ciudadanía" y expresa la pretensión de tratarlos también a ellos como participantes en la comunicación y miembros de una misma comunidad política, definida por los valores expresados en las normas quebrantadas ${ }^{31}$.

Esta pretensión inclusiva respecto de los acusados, que debieran ser respetados como sujetos con quienes estamos dispuestos a hablar y a quienes estamos dispuestos a escuchar, resulta, por cierto, especialmente difícil de aceptar e incluso quizá contra intuitiva en contextos de transición política, si pensamos que las atrocidades en las que consisten los delitos que se les atribuyen suponen, la negación a sus víctimas de la común pertenencia a una comunidad política - $\mathrm{e}$ incluso, como sugiere la emergencia de la categoría de los delitos de lesa humanidad para referir a esta clase de crímenes, a la comunidad más básica, en la humanidad.

Pero lo que está en juego es que, como argumenta Duff abordando, precisamente, esta dificultad, "no tendría sentido llamar a responder a un genuino monstruo amoral"32.

\footnotetext{
${ }^{29}$ Lo pone de relieve también Duff en un trabajo específicamente referido al rol de los procesos penales en los contextos de transición: DUFF, Antony, "Process, not punishment: The importance of criminal trials for transitional and transnational justice”, Minnesota Legal Studies Research Paper No. 14-03 (2014), pp. 12-13. Dicho en términos negativos, la falta de esa respuesta apropiada, a través de la cual la comunidad comparte el agravio sufrido, implicaría la negación a las víctimas de la posición de miembros de la comunidad protegidos por sus leyes.

${ }^{30}$ Las tres citas anteriores son de AGAMBEN, Giorgio, Homo sacer. El poder soberano y la nuda vida, Valencia: Pre-Textos, 2013, pp. 217-8.

${ }^{31}$ DUFF, "Process, not punishment..", cit. nota $\mathrm{N}^{\circ} 29$, p. 17.

${ }^{32}$ DUFF, Antony, "Can we punish the perpetrators of atrocities?", en BRUDHOLM, Thomas y CUSHMAN Thomas (eds.), The religious in responses to mass atrocity: Interdisciplinary perspectives, Cambridge, UK, Cambridge University Press, 2009, pp. 79-104, p. 99.
} 


\section{Polít. crim. Vol. 14, No 27 (Julio 2019), Art. 2, pp. 47-64 [http://politcrim.com/wp-content/uploads/2019/06/Vol14N27A2.pdf]}

"Es posible que el llamado a responder esté sustentado en la rabia, la indignación, el odio, incluso el desprecio y la repugnancia (...), pero él debe dirigirse al acusado como alguien capaz de entender (si sólo escuchara) aquello que decimos, y capaz de responder apropiadamente frente a eso (incluso aunque estemos empíricamente seguros de que no lo hará); como alguien de quien tiene sentido esperar (no importa cuán empíricamente vana sepamos que esa esperanza es) que pueda llegar a enfrentar la terrible verdad de lo que ha hecho. Y lo mismo es cierto respecto de la pena entendida como un intento de comunicación moral: la pena debe ser administrada con la esperanza (aunque sea vana) de que el sujeto llegue a verla como aquello que debe sufrir por lo que ha hecho y llegue a aceptarla como una penitencia (secular) apropiada; lo que significa que debemos tratarlo como alguien que puede ser llevado a una comprensión contrita de sus de sus crímenes y de su castigo"33.

Estas pretensiones normativas, aun cuando resulten, como se sugiere en la cita, empíricamente vanas, permiten pensar a los procesos penales en contextos transicionales como una instancia en la que la comunidad política, negada antes a través del terror, recobrara y expresara su voz, precisamente, común, para dirigir a quien es acusado como perpetrador la pretensión comunicativa de que responda, de que se explique y de que reconozca, en caso de ser condenado, la justificación del reproche expresado a través de la pena. De ese modo se vuelven a tejer los hilos de la comunidad política como comunidad normativa que incluye al acusado o condenado, que por eso debe responder. La atribución de responsabilidad supone, en este sentido, la inclusión del victimario; y su exclusión será, en cambio, la estrategia que de hecho muchos victimarios probablemente sigan, negándose a responder.

\section{La concepción comunicativa y las objeciones a la persecución penal de las atrocidades masivas}

\subsection{Las objeciones a las justificaciones consecuencialistas}

Además de aportar, como hemos visto, algunas claves relevantes para la justificación de la persecución penal en contextos de transición política, la concepción comunicativa de la pena y el proceso penal permite eludir también algunas de las objeciones que ella suele recibir.

No resulta afectada, en primer lugar, por el argumento de la improbable eficacia preventiva del derecho penal en las circunstancias excepcionales en las que la violencia política tiene lugar -una dificultad que Kircheimer extremaba cuando se refería, incluso, a un posible efecto contraproducente de la persecución penal al inducir a los criminales de guerra a luchar hasta el final en lugar de rendirse y enfrentar acusaciones de crímenes de guerra ${ }^{34}$. Desde la perspectiva de las teorías comunicativas, no hay fines extrínsecos que la pena deba cumplir. Su justificación reside en el merecimiento del sujeto a quien se comunica el reproche y no en la obtención, mediante la pena, de otros fines. De hecho, las teorías

\footnotetext{
${ }^{33}$ DUFF, Antony, "Can we punish...", cit. nota $\mathrm{N}^{\circ} 33$, p. 99.

${ }^{34}$ KIRCHHEIMER Political justice. The use of legal procedure for political ends, Princeton: Princeton University Press, 1961.
} 


\section{ACCATINO, Daniela “¿Por qué no a la impunidad? Una mirada desde las teorías comunicativas al papel de la persecución penal en la justicia de transición”.}

comunicativas pretenden distanciarse del instrumentalismo de las aproximaciones preventivas y revindican la calidad del sujeto penado como agente moral, tratado a través del reproche como sujeto responsable y no como objeto de una intervención útil al logro de otros fines. De modo que las eventuales consecuencias preventivas favorables de la imposición de la pena constituirán, desde esta perspectiva, por así decirlo, externalidades positivas, irrelevantes desde el punto de vista de su justificación ${ }^{35}$. Y si esos efectos son improbables, eso resulta igualmente irrelevante, dado el merecimiento, para su justificación.

Tampoco afectan a la justificación propuesta las objeciones que ponen de relieve el riesgo que la persecución penal en contextos de transición se transforme en un espectáculo diseñado para el logro de fines ajenos a la determinación imparcial de la responsabilidad del acusado, como podría ocurrir, en cambio, cuando se defiende el recurso a ella para favorecer la clarificación y el registro histórico de lo ocurrido, o para realizar de fines didácticos o de construcción de una memoria colectiva respecto de ese pasado traumático ${ }^{36}$. Como puso de relieve Hannah Arendt criticando la actitud del fiscal en el juicio contra Eichmann, esa instrumentalización del juicio representa un peligro para las garantías del debido proceso, que podrían ser sacrificadas en el altar de esos fines extrínsecos, y en último término, suscita el riesgo de condenas insuficientemente justificadas en pruebas referidas a la responsabilidad individual del acusado, que terminen usándolo como chivo expiatorio. $^{37}$

La justificación de la persecución penal que aquí ha sido esbozada no le atribuye en cambio al proceso penal en contextos de transición otro fin que el que precisamente reclamaba Arendt como legítimo, el de "hacer justicia al acusado", llamándolo a responder del delito

\footnotetext{
${ }^{35}$ Cfr., usando esa imagen, MAÑALICH, Juan Pablo, Terror, pena y amnistía. El derecho penal ante el terrorismo de Estado, Santiago de Chile: Flandes Indiano, 2010, pp. 84-5.

${ }^{36}$ Cfr., por ejemplo, en este sentido; NINO, Carlos S., Juicio al mal absoluto, Buenos Aires: Ariel, 2006; KOSKENNIEMI, Martti, "Between impunity and show trials", Max Plank Yearbook of United Nations law, Vol. 6 (2002), pp. 1-35; DOUGLAS, Lawrence, "The didactic trial: Filtering history and memory in the courtroom", European Review, Vol $14 \mathrm{No}^{\circ} 4$ (2006), pp. 513-522 y, del mismo autor, "History and memory in the courtroom: Reflections on perpetrator trials" en REGINBOGIN, Herbert y SAFFERLING, Christoph (eds.), The Nuremberg Trials. International Criminal Law since 1945, Munich: Sauer Verlag, 2006, pp. 95105 y HOL, Antoine "The theatre of justice: on educational meaning of criminal trials", en BRANTS, Chrisje, HOL, Antoine y SIEGEL, Dina (eds.), Transitional justice. Images and memories, Farnham: Ashgate.2013, pp. 71-86. Para una excelente discusión teórica de las relaciones entre persecusión penal del terror estatal y memoria colectiva, cfr. OSIEL, Mark, Mass atrocity, collective memory and the law, New Brunswick: Transaction Publishers, 1997, passim.
}

${ }^{37}$ Cfr. ARENDT, Hannah, Eichmann en Jerusalén, Barcelona: Lumen, 2013 (1963), p. 416: “(...) el proceso debía celebrarse con la finalidad de hacer justicia, nada más", y p. 433: "(l)a cuestión de la culpa o la inocencia individual, el acto de hacer justicia tanto al acusado como a la víctima, es la única finalidad de un tribunal de lo criminal". La conexión general entre el lugar del merecimiento en la justificación de la pena y la justificación de las garantías procesales penales y, en especial, de un estándar de prueba que evite en mayor grado el riesgo de condenas erróenas, es puesta de relieve entre nosotros por VALENZUELA, Jonatan, "El lugar del merecimiento: intuiciones sobre las relaciones entre derecho penal y derecho procesal penal", en Id., Hechos, pena y proceso, Santiago de Chile: Rubicón Editores, 2017, pp. 35-46, especialmente pp. 45-6. 
que se le imputa. Es haciendo justicia al acusado que el proceso hace justicia también, como respuesta debida ante un agravio público, a la víctima y al resto de los ciudadanos.

\title{
4.2. Las objeciones a la capacidad del derecho penal ordinario de dar cuenta del terror burocrático
}

El argumento, ya anticipado, de la inadecuación de las categorías ordinarias de la responsabilidad penal para dar cuenta de la naturaleza distintiva y sin precedente de las atrocidades masivas, es menos fácil de eludir. Para considerarlo, me centraré en la forma en que este argumento fue planteado por Arendt y distinguiré dos dimensiones a las que esta suerte de ceguera del derecho penal puede ser referida: a las categorías con que el derecho penal ordinario define los tipos penales y a las categorías asociadas a la atribución de responsabilidad individual.

Un locus clásico de la primera formulación del argumento se encuentra el siguiente texto de Arendt sobre el juicio a Eichmann:

\begin{abstract}
“(...) del mismo modo que el asesinato es objeto de persecución debido a que conculca la ley de la comunidad, y no porque se haya privado a tal o cual familia de aquel miembro que con su trabajo ganaba el pan de todos, del esposo y padre, igualmente podemos decir que los modernos asesinos masivos, funcionarios del Estado, deben ser perseguidos debido a que han trasgredido el orden imperante en el género humano, y no porque hayan dado muerte a millones de seres: nada hay más pernicioso para la comprensión de estos nuevos delitos o nada hay que obstaculice mayormente la formación de un código internacional que sea de aplicación a aquellos, que la difundida falsa creencia en que el delito de asesinato y el delito de genocidio son esencialmente iguales, y que, en consecuencia, el segundo 'no es un delito nuevo, en puridad'. La esencia del segundamente nombrado delito consiste en que quebranta un orden distinto y perjudica una comunidad distinta". ${ }^{38}$
\end{abstract}

Lo que la aplicación de los tipos penales ordinarios dejaría sin representación es, desde esta perspectiva, la radicalidad de un agravio que por su dimensión política y burocrática no resulta meramente equivalente a la suma de los agravios individuales cometidos. ${ }^{39}$

Sin perjuicio de que esta objeción pudiera haberse remediado hacia el futuro a través de la incorporación de las nuevas categorías con que se tipifican los delitos de lesa humanidad y el genocidio (una evolución que no consideraré aquí en detalle, pero parece responder a la intuición expresada por Arendt), pareciera inevitable conceder que cuando se aplican tipos penales ordinarios, lo que se reprocharía sería, por así decirlo, la dimensión exclusivamente individual del injusto cometido (no obstante que, como hemos dicho, en todo caso el proceso penal y la pena visibilizarían la dimensión pública de ese agravio individual).

\footnotetext{
${ }^{38}$ ARENDT, Eichmann en Jerusalén, cit. nota N³7, pp. 396-7.

${ }^{39}$ En el contexto de la discusión chilena, el argumento apunta a la "normalización" que la estrategia de la persecución penal implicaría respecto de la función "fundacional” que esa violencia sistemática cumplió respecto del régimen político asociado a la Constitución de 1980: cfr. ATRIA, "La hora del derecho...", cit. nota $\mathrm{N}^{\circ} 19$, y MAÑLICH, Terror, pena..., cit. nota $\mathrm{N}^{\circ} 35$, especialmente pp. 9-11.
} 
Este déficit de la respuesta penal puede ser interpretado, me parece, en dos sentidos. En un primer sentido se trataría de un déficit epistémico: la dimensión política y burocrática del mal radical resultaría jurídicamente irrelevante y no sería abordada por el proceso penal. En un segundo sentido constituiría un déficit retributivo: el reproche penal no sería proporcionado a la entidad del mal, no lograría hacer justicia, en este sentido, a la gravedad de las atrocidades cometidas.

Respecto del primer sentido cabe observar, primero, que la dimensión burocrática sí resulta jurídicamente relevante y es, de hecho, objeto de discusión y de prueba en los procesos penales domésticos en contextos transicionales, para la atribución de responsabilidad a los autores directos y mediatos. Es precisamente porque se prueba en esos procesos la existencia de una organización burocrática en cuya red de centros de tortura y muerte fue cometido el hecho delictivo individual que puede imputarse responsabilidad no sólo a los ejecutores materiales sino también a los mandos superiores en esa organización. Es cierto que una reconstrucción global de esa dimensión burocrática y de su sentido político puede resultar mejor articulada en un proceso por genocidio o por crímenes de lesa humanidad o, cuando esos nuevos tipos no resultan aplicables, en un informe de una Comisión de Verdad, más que a través de un rompecabezas de procesos y sentencias judiciales referidos a casos individuales (y de hecho esos informes son a menudo utilizados, luego, como fuente de información en los procesos). Pero la contribución única que los procesos penales pueden realizar, aun aplicando tipos penales ordinarios referidos a agravios individuales, consiste en dar cuenta, a través del llamado individualizado a responder, de que los hechos en que se manifiesta el terror político no son un infortunio que sucede, como una inundación o un desastre natural (retomando los símiles que Atria utilizaba), sino que ejecutan a través de acciones de individuos que constituyen agravios públicos de los que, precisamente, cabe llamar a responder y reprochar.

Con respecto al déficit retributivo de la respuesta penal doméstica por delitos ordinarios individuales frente a la extraordinaria gravedad de las atrocidades masivas, creo que el argumento apunta efectivamente a una dificultad que afecta la capacidad expresiva y comunicativa de esas penas. Frente a ella cabe advertir, sin embargo, que la (im)posibilidad de una pena proporcional a esta clase de agravios parece en sí misma, también para las tipificaciones contemporáneas del delito de genocidio o de crímenes de lesa humanidad, una aporía irresoluble. Una aporía que Arendt advirtió, al mismo tiempo que notaba, sin embargo, que "nuestro sentido de justicia encontraría intolerable renunciar al castigo y dejar que queden impunes quienes asesinaron a miles, cientos de miles y millones". ${ }^{40}$ No parece, en este sentido, que la imposibilidad de una retribución adecuada justifique el abandono de toda pretensión de retribución comunicativa.

Para terminar, quisiera advertir que la objeción que se refiere a la inadecuación de las categorías de la responsabilidad penal individual pone un segundo desafío a la justificación de la persecución penal en contextos de transición política. La cuestión ya no apunta aquí a la incapacidad del derecho y del proceso penal de dar cuenta del carácter político y burocrático de las atrocidades masivas, sino a cómo la burocracia puede volver irrelevante

${ }^{40}$ ARENDT, Hannah, "Auschwitz on trial" (1966), en ID., Responsibility and judgment, New York: Schocken, 2003, pp. 227-256. 
la agencia y la motivación individual, y poner en cuestión la posibilidad de la responsabilidad individual en los términos en que es concebida ordinariamente por el derecho penal. Se trata de un punto que también pone de relieve Arendt en sus reflexiones sobre la "terrorífica normalidad" de Eichmann y sobre este nuevo tipo de delincuente que "comete sus delitos en circunstancias que le impiden saber o intuir que realiza actos de maldad" $"$.

Se trata de un punto importante, cuya respuesta supondría evaluar los esfuerzos de la dogmática penal en la reconstrucción de las categorías referidas a la participación penal, para analizar si logran integrar en un mismo aparato conceptual los presupuestos de la responsabilidad individual y esa suerte de banalidad del mal burocrático.

Examinar detenidamente esta dimensión de los esfuerzos por articular una "teoría jurídica de la atrocidad"42 escapa a las posibilidades de este trabajo. Pero sí cabe advertir que ellos debieran hacer posible que cada proceso penal dirigido contra los actores del terror burocrático concluya con las palabras con que Arendt cierra su Epílogo al texto sobre Eichmann en Jerusalén, las palabras que los juzgadores hubieran debido atreverse a dirigirle al acusado para "mostrar públicamente que se hace justicia":

"Si aceptamos, a efectos didácticos, que tan solo a la mala suerte se debió que llegaras a ser voluntario instrumento de una organización de asesinato masivo, todavía queda el hecho de haber, tú, cumplimentado y, en consecuencia, apoyado activamente, una política de asesinato masivo".

\footnotetext{
${ }^{41}$ ARENDT, Eichmann en Jerusalén, cit. nota $\mathrm{N}^{\circ} 37$, p. 403.

42 DOUGLAS, Lawrence, "Shattering Nuremberg. Toward a jurisprudence of atrocity", Harvard International Review (2007) (http://hir.harvard.edu/shattering-nuremberg/). Cfr. también, OSIEL, Mark, Making sense of mass atrocity, Cambridge: Cambridge University Press, 2009, passim.
} 
ACCATINO, Daniela “¿Por qué no a la impunidad? Una mirada desde las teorías comunicativas al papel de la persecución penal en la justicia de transición”.

\section{Bibliografía}

AGAMBEN, Giorgio, Homo sacer. El poder soberano y la nuda vida, Valencia: PreTextos, 2013.

ARENDT, Hannah, Eichmann en Jerusalén, Barcelona: Lumen, 2013 (1963).

ARENDT, Hannah, "Auschwitz on trial" (1966), en ID., Responsibility and judgment, New York: Schocken, 2003.

ATRIA, Fernando, "La hora del derecho: los 'derechos humanos' entre la política y el derecho", Estudios Públicos, $\mathrm{N}^{\circ} 91$ (2003), pp. 45-89.

BOUVIER, Hernán, GULLI, Belén y IOSA, Juan (eds.), El juzgamiento de los delitos de lesa humanidad en la Argentina postdictatorial, Córdoba: Ferreyra Editores, 2014.

COLLINS, Cath, Post-transitional justice. Human rights trials in Chile and El Salvador, Pennsylvania: The Pennsylvania State University Press, 2010.

COLLINS, Cath, "La política de la justicia: Chile más allá del caso Pinochet", en COLLINS, Cath, HITE, Katherine y JOIGNANT, Alfredo (eds.), Las políticas de la memoria en Chile: desde Pinochet a Bachelet, Santiago: Ediciones Universidad Diego Portales, 2013, pp. 85-115.

COLLINS, Cath, "Human rights defense in and through the courts in (post) Pinochet Chile", Radical History Review, $\mathrm{N}^{\circ} 124$ (2016) pp. 129-140.

COLLINS, Cath et. al., "Verdad, justicia, reparaciones y memoria", en CENTRO DE DERECHOS HUMANOS DE LA UNIVERSIDAD DIEGO PORTALES, Informe anual sobre derechos humanos en Chile 2017 (http://www.derechoshumanos.udp.cl/derechoshumanos/index.php/informe-ddhh2017).

COLLINS, Cath, SKAAR, Elin y GARCÍA-GODOS Jemima (eds.), Transitional justice in Latin America: the long road from impunity towards accountability, Abington: Routledge, 2016

DE GREIFF, Pablo, “Theorizing transitional justice”, Nomos, vol. LI (Transitional Justice) (2012), pp. 31-77

DOUGLAS, Lawrence, "The didactic trial: Filtering history and memory in the courtroom", European Review, Vol 14, No 4 (2006), pp. 513-522.

DOUGLAS, Lawrence, "History and memory in the courtroom: Reflections on perpetrator trials" en REGINBOGIN, Herbert y SAFFERLING, Christoph (eds.), The Nuremberg Trials. International Criminal Law since 1945, Munich: Sauer Verlag, 2006.

DOUGLAS, Lawrence, "Shattering Nuremberg. Toward a jurisprudence of atrocity", Harvard International Review (2007).

DUFF, Antony, Punishment, communication and community, Oxford: Oxford Universtity Press, 2001.

DUFF, Antony, Answering for crime, Oxford and Portland: Hart Publishing, 2007.

DUFF, Antony, "Can we punish the perpetrators of atrocities?", en BRUDHOLM, Thomas y CUSHMAN Thomas (eds.), The religious in responses to mass atrocity: Interdisciplinary perspectives, Cambridge, UK, Cambridge University Press, 2009, pp. 79-104. 
DUFF, Antony, "Process, not punishment: The importance of criminal trials for transitional and transnational justice", Minnesota Legal Studies Research Paper No. 14-03 (2014) pp. 12-13.

DUFF, Antony, FARMER, Lindsay, MARSHALL, Sandra y TADROS, Victor, The trial on trial III: Towards a normative theory of criminal trial, Oxford and Portland: Hart Publishing, 2006.

FEINBERG, Joel, "The expressive function of punishment", en ID., Doing and deserving, Princeton: Princeton University Press, 1970, pp. 95-118.

FERNÁNDEZ, Karinna y SFERRAZZA Pietro, "La aplicación de la prescripción gradual en casos de violaciones de derechos humanos", Estudios Constitucionales, Vol. 7 , No 1 (2009), pp. 299-330.

FORNASARI, Gabriele, Giustizia di transizione e diritto penale, Torino: Giappichelli, 2013.

GARGARELlA, Roberto, Castigar al prójimo. Por una refundación democrática del derecho penal, Buenos Aires: Siglo XXI, 2016.

GÜNTHER, Klaus “The criminal law of 'guilt' as subject of a politics of remembrance in democracies', en CHRISTODOULIDIS, Emilios y VEITCH, Scott (eds.), Lethe's law, Oxford: Hart Publishing, 2001, pp. 3-15.

GÜNTHER, Klaus, "Criminal law, crime and punishment as communication", Normative Orders Working Paper 02/2014, Normative Orders Cluster of Excellence at Goethe University Frankfurt/Main (http://publikationen.ub.unifrankfurt.de/frontdoor/index/index/docId/34663).

HEBERER, Patricia y MATTHAÜS, Jürgen (eds.), Atrocities on trial. Historical perspectives on the politics of prosecuting war crimes, Lincoln: University of Nebraska Press, 2008.

HILBINK, Lisa, Jueces y política en democracia y dictadura. Lecciones desde Chile, México DF: FLACSO, 2014.

HOL, Antoine "The theatre of justice: on educational meaning of criminal trials", en BRANTS, Chrisje, HOL, Antoine y SIEGEL, Dina (eds.), Transitional justice. Images and memories, Farnham: Ashgate, 2013, pp. 71-86.

KIRCHHEIMER Political justice. The use of legal procedure for political ends, Princeton: Princeton University Press, 1961.

KOSKENNIEMI, Martti, "Between impunity and show trials", Max Plank Yearbook of United Nations law, Vol. 6 (2002), pp. 1-35.

KRITZ, Neil, Transitional justice: how emerging democracies reckon with former regimes, Washington: USIP, 1995.

MAÑALICH, Juan Pablo, Terror, pena y amnistía. El derecho penal ante el terrorismo de Estado, Santiago de Chile: Flandes Indiano, 2010.

MAÑALICH, Juan Pablo, "Responsabilidad, autoridad y democracia. Una exploración crítica de la filosofía del derecho penal de Antony Duff", Discusiones, № 17 (2016), pp. 167-219.

MARGARELL, Luisa y FILIPPINI, Fernando (eds.), La justicia penal en la transición peruana, Nueva York: ICTJ, 2006.

McGONINGLE, Brianne, "Nuremberg's legacy within transitional justice: prosecutions are here to stay", Washington University Global Studies Law Review, Vol. 15, Issue 4 (2016), pp. 559-574. 
NINO, Carlos S., Juicio al mal absoluto, Buenos Aires: Ariel, 2006.

OSIEL, Mark, Mass atrocity, collective memory and the law, New Brunswick: Transaction Publishers, 1997.

OSIEL, Mark, Making sense of mass atrocity, Cambridge: Cambridge University Press, 2009.

PAIGE, Arthur, "How 'transitions' reshaped human rights: a conceptual history of transitional justice", Human Rights Quarterly, vol. 31 (2009), pp. 321-367.

PRIMORATZ, Igor, "Punishment as language", Philosophy, N 64 (1989), pp. 187-205.

QUINTEROS, Víctor Manuel (ed.), Judicialización de violaciones de derechos humanos: aportes sustantivos y procesales, Lima: AECID, 2010.

SIKKINK, Katherine, The justice cascade. How human rights prosecutions are changing world politics, New York - London: W. W. Norton \& Company, 2011.

STERN, Steve J., "Memory. The curious history of a cultural code word", Radical History Review, No 124 (2016), pp. 117-128.

TEITEL, Ruti, Transitional justice, Oxford: Oxford University Press, 2000.

TEITEL, Ruti, "Transitional justice and judicial activism -a right to accountability?", Cornell International Law Review, Vol. 48 (2015), pp. 385-422.

VALENZUELA, Jonatan, "La pena como penitencia secular. Apuntes sobre el sentido de la ejecución de la pena", Revista de Derecho (Valdivia), Vol. XXIII, No 1 (2010), pp. 255-268.

VALENZUELA, Jonatan, Hechos, pena y proceso, Santiago de Chile: Rubicón Editores, 2017. 